\title{
Residual pulmonary hypertension after pulmonary endarterectomy: A meta-analysis
}

\author{
Wan Chin Hsieh, MD, ${ }^{\text {a,b }}$ Pavel Jansa, MD, PhD, ${ }^{\mathrm{c}}$ Wei Chun Huang, MD, PhD, ${ }^{\text {de, }, \mathrm{f}}$ Matus Nižnanský, MD, ${ }^{\mathrm{b}}$ \\ Mohamend Omara, $\mathrm{MD},{ }^{\mathrm{g}}$ and Jaroslav Lindner, $\mathrm{MD}, \mathrm{PhD}^{\mathrm{b}}$
}

\section{ABSTRACT}

Objective: Chronic thromboembolic pulmonary hypertension is surgically treated through pulmonary endarterectomy. Although pulmonary endarterectomy is the treatment of choice for chronic thromboembolic pulmonary hypertension in terms of both functional outcomes and survival, many patients experience persistent pulmonary hypertension after pulmonary endarterectomy. The study objective was to calculate the pooled estimates of outcomes after pulmonary endarterectomy, including persistent pulmonary hypertension.

Methods: Meta-analyses were conducted on published studies reporting residual/ persistent/recurrent pulmonary hypertension in 4868 patients with chronic thromboembolic pulmonary hypertension after pulmonary endarterectomy. The rate of persistent pulmonary hypertension and change in mean pulmonary artery pressure, pulmonary vascular resistance, and 6-minute walk distance after pulmonary endarterectomy were outcomes of interest.

Results: Twenty-five percent of patients with chronic thromboembolic pulmonary hypertension were diagnosed with persistent pulmonary hypertension after pulmonary endarterectomy. Pulmonary endarterectomy reduced mean pulmonary artery pressure and pulmonary vascular resistance by approximately $21 \mathrm{~mm} \mathrm{Hg}$ (standardized mean difference, $1.75 ; 95 \%$ confidence interval, -1.62 to 1.88 ; $P<.00001$ ) and 561 dyn.s $/ \mathrm{cm}^{5}$ (standardized mean difference, $1.64 ; 95 \%$ confidence interval, -1.58 to $1.70 ; P<.00001$ ), respectively. Conversely, 6 -minute walk distance increased by $96 \mathrm{~m}$ (standardized mean difference, $-0.83 ; 95 \%$ confidence interval, -0.91 to $-0.76 ; P<.00001$ ) after pulmonary endarterectomy.

Conclusions: Pulmonary endarterectomy is the gold standard treatment for chronic thromboembolic pulmonary hypertension and provides immediate correction of hemodynamic parameters in most patients. However, in up to one quarter of operable cases, pulmonary hypertension persists after surgery. In those patients with persistent pulmonary hypertension, continued medical management with newer agents may be required to improve pulmonary hemodynamics and, therefore, patient outcomes. (J Thorac Cardiovasc Surg 2018;156:1275-87)

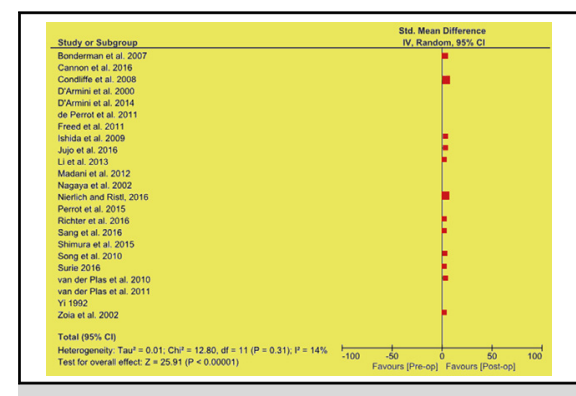

Forest plot of MPAP in patients with CTEPH after PEA

\section{Central Message}

PEA is a common treatment for chronic $\mathrm{PH}$ and improved hemodynamic parameters and physical status. Medical management is required if PH persists.

\section{Perspective}

PEA is the current gold standard for treating CTEPH. Although PEA improves hemodynamic outcomes and physical condition, continued medical management is required in patients with persistent $\mathrm{PH}$ after PEA. Our study can help clinicians make a better evidence-based informed decision on treating patients with CTEPH.

See Editorial Commentary page 1288.
Chronic thromboembolic pulmonary hypertension (CTEPH) is a pulmonary vascular disease resulting from the chronic obstruction of major pulmonary arteries. The disease typically results from unresolved thrombi that if

\footnotetext{
From the ${ }^{a}$ First Faculty of Medicine, Charles University, Prague, Czech Republic; ${ }^{\mathrm{b}}$ 2nd Department of Cardiovascular Surgery, First Faculty of Medicine, Charles University and General University Hospital in Prague, Prague, Czech Republic; ${ }^{\mathrm{c}}$ Pulmonary Hypertension Center, 2nd Internal Clinic, General University Hospital in Prague, First Faculty of Medicine, Charles University, Prague, Czech Republic; ${ }^{\mathrm{d} C}$ Critical Care and Cardiovascular Medical Center, Kaohsiung Veterans General Hospital, Kaohsiung, Taiwan; ${ }^{\mathrm{e} C o l l e g e ~ o f ~ M e d i c i n e, ~ N a t i o n a l ~ Y a n g-M i n g ~ U n i v e r-~}$ sity, Taipei, Taiwan; ${ }^{\mathrm{f}}$ Department of Physical Therapy, Fooyin University, Kaohsiung, Taiwan; and ${ }^{\mathrm{g}}$ Department of Thoracic and Cardiovascular Surgery, Research Institute, Cleveland Clinic, Cleveland, Ohio.
}

left untreated undergo fibrotic transformation, leading to mechanical obstruction of the pulmonary arteries. ${ }^{1}$ Microvessel remodeling comparable to the arteriopathy seen in pulmonary arterial hypertension (PAH) is also believed to

The work was supported by Grant SVV-2017-260 372

Received for publication Dec 1, 2017; revisions received April 20, 2018; accepted for publication April 26, 2018; available ahead of print June 12, 2018.

Address for reprints: Jaroslav Lindner, MD, PhD, 2nd Department of Cardiovascular Surgery, First Faculty of Medicine, Charles University and General University Hospital in Prague, Prague, Czech Republic (E-mail: jaroslav.lindner@1f1.cuni. $\mathrm{cz})$.

$0022-5223 / \$ 36.00$

Copyright (C) 2018 by The American Association for Thoracic Surgery

https://doi.org/10.1016/j.jtcvs.2018.04.110 


\section{Abbreviations and Acronyms}

$\mathrm{CTEPH}=$ chronic thromboembolic pulmonary hypertension

df $=$ degrees of freedom

mPAP $=$ mean pulmonary artery pressure

PEA = pulmonary endarterectomy

$\mathrm{PH}=$ pulmonary hypertension

PVR = pulmonary vascular resistance

$\mathrm{RPH}=$ residual pulmonary hypertension

6MWD $=6$-minute walk distance

WHO $=$ World Health Organization

Scanning this QR code will take you to a procedural video.

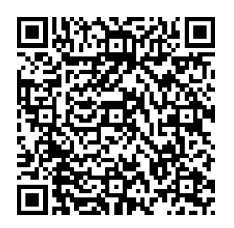

significantly contribute to CTEPH pathogenesis. ${ }^{2}$ Pulmonary embolism (PE) is a common preceding condition to $\mathrm{CTEPH}$, and, as such, CTEPH is typically thought of as a rare complication of PE. According to an international prospective registry report, approximately $80 \%$ of patients with CTEPH had a history of PE. ${ }^{3}$ In addition, recurrent venous thromboembolism and idiopathic $\mathrm{PE}$ were both found to be associated with an increased risk of CTEPH. ${ }^{4}$ Although the true prevalence and incidence of CTEPH are unknown, it is believed to occur in up to 5 individuals per million population per year or in up to $9.1 \%$ of patients within the first 2 years after an acute PE event. ${ }^{5,6}$

The typical diagnostic criteria for CTEPH are mean pulmonary artery pressure (mPAP) of $25 \mathrm{~mm} \mathrm{Hg}$ or more, pulmonary capillary wedge pressure of $15 \mathrm{~mm} \mathrm{Hg}$ or less after 3 or more months of effective anticoagulation treatment in conjunction with chronic occlusive emboli or thrombi in the pulmonary arteries, and at least 1 segmental perfusion defect on ventilation/ perfusion lung scans. ${ }^{7,8}$ One major clinical challenge is differentiating between CTEPH and PAH. However, CTEPH has several distinctive features compared with PAH, including nonhomogeneous distribution of the disease, an episodic disease course, and more frequent occurrence of hemoptysis. A definitive diagnosis can be established by conventional or computed tomography (CT), pulmonary angiogram, magnetic resonance angiography (MRA), and right heart catheterization. ${ }^{3}$

Occlusion of the pulmonary arteries can result in an increase in pulmonary vascular resistance (PVR), progressive pulmonary hypertension $(\mathrm{PH})$, and subsequent right heart failure. Therefore, CTEPH is progressive and often fatal, with a median survival in severe untreated CTEPH reported to be as low as $10 \%$ to $20 \%$ after 2 to 3 years. ${ }^{9,10}$ Early diagnosis is critical for the proper management of this disorder. Furthermore, CTEPH is potentially curable with pulmonary endarterectomy (PEA) surgery. This surgical procedure removes the impeding thromboembolic matter and can result in significant symptomatic and prognostic improvements in eligible patients. ${ }^{11}$ The surgery is complex and requires a technically skilled and experienced surgeon. In addition, several important factors must be considered before a patient is deemed eligible for PEA, including comorbidities, advanced age, the accessibility of thromboembolic material, and the level of PVR. ${ }^{5}$ Patients with less than $50 \%$ in PVR post-PEA and with PVR greater than 1200 dyn.s $/ \mathrm{cm}^{5}$ are ineligible for surgery. ${ }^{12-14}$ Expert centers tend to have excellent success rates, with periprocedural mortality rates of less than $2 \%$ to $5 \% .{ }^{15}$

Although PEA is the gold standard treatment for CTEPH, the disease process is complex, and several patients present with persistent or residual pulmonary hypertension (RPH) after PEA. ${ }^{16-20}$ This can be explained by the 2compartment model proposed by Moser and Braunwald in $1973 .{ }^{21}$ In this model, patients with operable CTEPH may develop a distal, secondary, small-vessel arteriopathy in the nonobstructed vascular beds. ${ }^{20}$ However, few centers have comprehensively evaluated these patients, and the estimates of the number of patients with RPH after PEA vary greatly from $5 \%$ to $35 \% .{ }^{17-20}$ Therefore, the current metaanalyses aimed to investigate the occurrence of RPH after PEA and compare changes in mPAP, PVR, and 6-minute walk distance (6MWD) after PEA.

\section{MATERIALS AND METHODS \\ Data Sources and Search Terms}

The search strategy was designed to identify full-length publications reporting RPH in patients with CTPEH. PubMed was searched using Medical SubHeading terms using the term "pulmonary hypertension/surgery," where "pulmonary hypertension" was defined as "increased vascular resistance in the pulmonary circulation, usually secondary to heart diseases or lung diseases." Embase and Medline databases were searched through Embase using the EMTREE terms "endarterectomy," "pulmonary hypertension," and "residual pulmonary hypertension." Filters were applied to select only English language publications reported on human subjects to reduce publication bias because of potential misinterpretation of research findings. Reference lists of the reviews and research articles were manually screened to identify further articles. Inclusion criteria included (1) studies reporting residual/persistent/recurrent $\mathrm{PH}$ in patients with CTPEH after PEA and (2) studies reporting change in mean pulmonary artery pressure (mPAP), PVR, and 6MWD after PEA. Abstracts, conference proceedings, posters, case series/reports, reviews, editorials, and non-English publications were excluded, because these gray literature usually omit the reporting of many relevant outcomes and therefore might contribute to reduced generalizability of research findings because of incomplete reporting of essential information for the analyses conducted in this study.

\section{Study Selection}

Any duplicate articles were removed. The titles and abstracts of the remaining articles were reviewed by 2 independent investigators (Figure 1) (Kappa index: $0.932,95 \%$ confidence interval [CI], 0.889-0.961; 


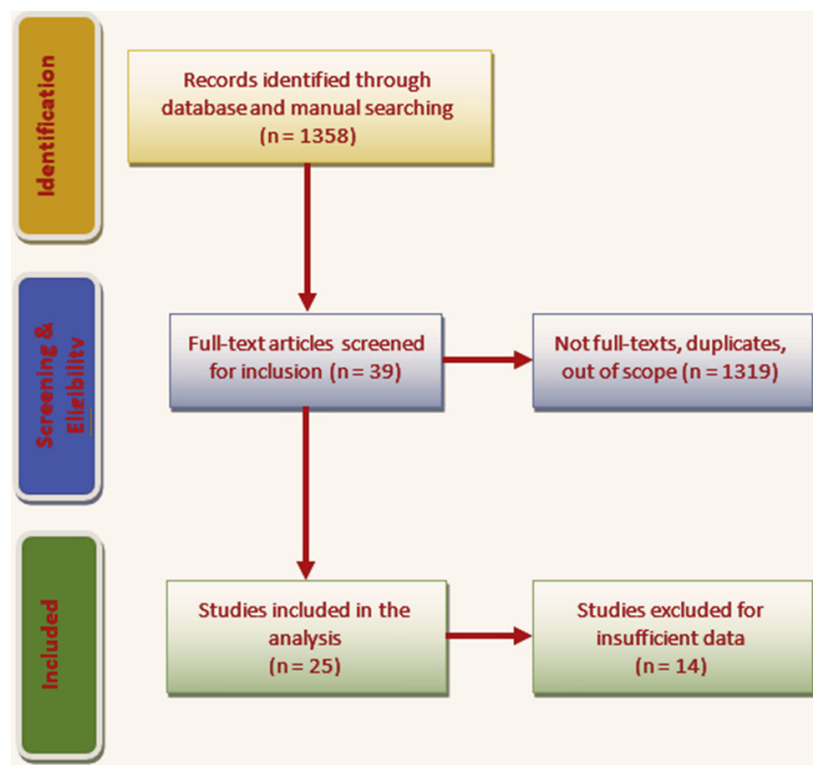

FIGURE 1. PRISMA flow diagram of the steps followed in the selection of studies per the inclusion criteria (Kappa index: 0.932; 95\% CI, 0.889$0.961 ; P<.001)$.

$P<.001)$ who were responsible for determining whether the articles were eligible for inclusion. To address any inconsistencies, the investigators compared lists before they reviewed the full text of the studies identified as eligible. When the final list of articles was complete, a third investigator resolved final discrepancies.

\section{Data Extraction and Meta-Analysis}

A standardized custom Excel sheet (Microsoft Corp, Redmond, Wash) was used to extract all the relevant and specific data on study characteristics, patient characteristics, diagnostic methods, surgical interventions, and outcomes. These data were extracted independently by 2 investigators (Figure 1) (Kappa index: 0.932; 95\% CI, 0.889-0.961; $P<.001$ ) and compared to resolve discrepancies. To calculate the rate of RPH after PEA and estimate the changes in MPAP, PVR, and 6MWD after PEA, 4 metaanalysis models were constructed: Model 1, estimation of the pooled event rate of residual PH after PEA; Model 2, post-PEA change in mPAP; Model 3, post-PEA change in PVR; and Model 4, post-PEA change in 6MWD.

Publication bias was qualitatively assessed via funnel plots and quantitatively evaluated by the Egger test. A qualitative estimate of statistical heterogeneity between studies was assessed using the Cochrane $Q$ test. For the chi-square test, a $P$ value of less than .05 was considered statistically significant. In the presence of significant heterogeneity, the $\mathrm{I}^{2}$ statistic was used to quantify the level of heterogeneity. The $\mathrm{I}^{2}$ value was interpreted on the basis of Hedges criteria, where $25 \%, 50 \%$, and $75 \%$ correspond to low, medium, and high heterogeneity, respectively. ${ }^{22}$

Statistical heterogeneity, Forest plots, and publication bias were conducted with Comprehensive Meta-analysis software (Biostat, Englewood, NJ). To accommodate between-study heterogeneity, the DerSimonian and Laird random-effects model was used for all meta-analysis models. ${ }^{23}$ Effect size was represented by the standardized mean difference (SMD), ${ }^{22}$ which indirectly reflects the difference between the interventions, in all included studies, because these studies did not use the same outcome measures.

\section{RESULTS}

\section{Study Selection and Characteristics of the Trials}

The databases and manual search retrieved 1358 English language journal articles. The titles and abstracts of these articles were screened to eliminate 1319 studies that were duplicates or abstracts, or studied different objectives. In the next phase, 39 full texts of articles were obtained and screened. Fourteen of these articles provided incomplete data and, not to impair the generalizability of research findings, were discarded from the articles assessed in this meta-analysis. The remaining 25 articles were included for meta-analysis. ${ }^{3,15,18-20,24-43}$ The flow chart of the studies evaluated is represented in Figure 1.

The characteristics of the included studies and their participants, along with the methods for diagnosing CTPEH, are summarized in Table 1. Six studies were conducted in Japan, 3 each in the United Kingdom, Canada, Italy, and Austria, 2 each in the Netherlands and China, and 1 each in the United States and Germany. One study had subjects from all over Europe. Twelve studies analyzed the patient records retrospectively, 3 studies did not report the study design clearly, and 10 studies recruited patients for a prospective analysis. A total of 4686 patients' data were available from these studies, with an average age range of 38 to 64 years with $22 \%$ to $85 \%$ male. Baseline and postsurgery measurements of the patients, along with follow-up times, are presented in Table 2.

\section{Residual Pulmonary Hypertension After Pulmonary Endarterectomy}

Eighteen studies reported RPH after PEA in patients with CTPEH. The heterogeneity between these studies was statistically significant (Cochran Q 300.4 [degrees of freedom $\left.[\mathrm{df}]=17] ; \mathrm{I}^{2} 94.3 ; P<.00001\right)$. A random effects model showed that $25 \%$ (95\% CI, 0.18-0.34) of the patients experienced RPH after PEA (Figure 2).

The funnel plot showed a likelihood of publication bias, because more studies were plotted on the left side. Duvall and Tweedie's trim and fill imputed no possibly missing studies. Egger's test $(\mathrm{B} 0=-3.42 ; 95 \% \mathrm{CI},-6.49$ to $\left.-0.35 ; \mathrm{t}=2.36 ; \mathrm{df}=16 ; P_{1 \text {-tailed }}=.02\right)$ showed that the publication bias was statistically significant.

\section{Mean Pulmonary Artery Pressure Before and After Pulmonary Endarterectomy}

Twenty-three studies reported changes in MPAP after PEA in patients with CTPEH. The heterogeneity between these studies was not statistically significant (chi-square 12.8 [df 11]; $\left.\mathrm{I}^{2} 14 \% ; P=.31\right)$. A random effects model showed that mPAP reduced by an average of $21.42 \mathrm{~mm}$ $\mathrm{Hg}$ after PEA (SMD, 1.75; 95\% CI, 1.62-1.88). This reduction was statistically significant $(P<.00001)$ (Figure 3$)$.

The funnel plot showed a likelihood of publication bias, because all the studies were plotted on the right side of the plot. Duvall and Tweedie's trim and fill imputed no possibly missing studies. Egger's test of the intercept $(\mathrm{B} 0-0.74$; $95 \% \mathrm{CI},-3.85$ to $\left.2.37 ; \mathrm{t}=0.49 ; \mathrm{df}=11 ; P_{1 \text {-tailed }} .31\right)$ 
TABLE 1. Study and patient characteristics of the included articles

\begin{tabular}{|c|c|c|c|c|c|c|c|c|}
\hline Study & Origin & Design & Subjects & Follow-up & Diagnostic methods & $\begin{array}{c}\text { Criteria for } \\
\text { RPH }\end{array}$ & Age (y) & Male (\%) \\
\hline $\begin{array}{l}\text { Yin and colleagues, }{ }^{24} \\
1992\end{array}$ & $\begin{array}{l}\text { Chinese (with } \\
\text { German data) }\end{array}$ & RTS & 32 & $>12 \mathrm{mo}$ & ABG, CXR, EKG & $>30 \mathrm{~mm} \mathrm{Hg}$ & 38 & 46 \\
\hline $\begin{array}{l}\text { D'Armini and } \\
\text { colleagues, }^{25} \\
2000\end{array}$ & Italy & RTS & 33 & $2 \mathrm{y}$ & $\begin{array}{l}\text { V/Q scan, CT, } \\
\text { CTPA }\end{array}$ & NR & 48 & 55 \\
\hline $\begin{array}{l}\text { Nagaya and colleagues, }{ }^{26} \\
2002\end{array}$ & Japan & NR & 34 & NR & $\mathrm{ABG}$ & NR & 49 & 38 \\
\hline $\begin{array}{l}\text { Zoia and colleagues, }{ }^{27} \\
2002\end{array}$ & Italy & PRS & 38 & $2 \mathrm{y}$ & RHC, PFT, ABG & NR & 51 & 50 \\
\hline $\begin{array}{l}\text { Ogino and colleagues, }{ }^{28} \\
2006\end{array}$ & Japan & RTS & 88 & $5 \mathrm{y}$ & $\begin{array}{l}\text { V/Q scan, RHC, } \\
\text { CTPA }\end{array}$ & NR & 52 & 40 \\
\hline $\begin{array}{l}\text { Bonderman and } \\
\text { colleagues, }{ }^{18} \\
2007\end{array}$ & Austria & RTS & 105 & $12 \mathrm{mo}$ & $\begin{array}{l}\text { CXR, EKG, PFT, } \\
\text { ABG, RHC, } \\
\text { V/Q scan, CT, } \\
\text { CTPA }\end{array}$ & $>25 \mathrm{~mm} \mathrm{Hg}$ & 52 & 47 \\
\hline $\begin{array}{l}\text { Condliffe and } \\
\text { colleagues, }^{19} \\
2008\end{array}$ & United Kingdom & RTS & 236 & $3 y$ & CTPA, RHC, EKG & NR & NR & NR \\
\hline $\begin{array}{l}\text { Ishida and colleagues, }{ }^{29} \\
2009\end{array}$ & Japan & PRS & 23 & 7-59 mo & RHC & NR & 54 & 57 \\
\hline $\begin{array}{l}\text { Song and colleagues, * } \\
2010\end{array}$ & China & RTS & 15 & $\geq 2 y$ & $\begin{array}{l}\text { V/Q scan, CTPA, } \\
\text { CT, RHC }\end{array}$ & NR & 42 & 80 \\
\hline $\begin{array}{l}\text { van der Plas and } \\
\text { colleagues, }{ }^{31} 2010\end{array}$ & Netherlands & RTS & 54 & $1 \mathrm{y}$ & CTPA, RHC & $>25 \mathrm{~mm} \mathrm{Hg}$ & 51 & 39 \\
\hline $\begin{array}{l}\text { Mayer and colleagues, }{ }^{3} \\
2011\end{array}$ & Europe & PRS & 386 & & $\begin{array}{l}\text { RHC, V/Q scan, } \\
\text { CT, CTPA }\end{array}$ & $>25 \mathrm{~mm} \mathrm{Hg}$ & 60 & 54 \\
\hline $\begin{array}{l}\text { Freed and colleagues, } \\
\quad 2011\end{array}$ & United Kingdom & PRS & 314 & & V/Q scan, CTPA & $\geq 30 \mathrm{~mm} \mathrm{Hg}$ & 55 & 54 \\
\hline $\begin{array}{l}\text { van der Plas and } \\
\text { colleagues, }{ }^{33} 2011\end{array}$ & Austria & NR & 96 & $>12 \mathrm{mo}$ & CTPA, RHC & $>25 \mathrm{~mm} \mathrm{Hg}$ & NR & NR \\
\hline $\begin{array}{l}\text { de Perrot and } \\
\text { colleagues, }{ }^{32} 2011\end{array}$ & Canada & RTS & 58 & $25 \mathrm{mo}$ & $\begin{array}{l}\text { V/Q scan, EKG, } \\
\text { CTPA, RHC }\end{array}$ & $>25 \mathrm{~mm} \mathrm{Hg}$ & 56 & 43 \\
\hline $\begin{array}{l}\text { Madani and colleagues, }{ }^{15} \\
2012\end{array}$ & United States & RTS & 1500 & $60 \mathrm{mo}$ & $\begin{array}{l}\text { CXR, EKG, } \\
\text { V/Q scan, RHC, } \\
\text { CT, CTPA }\end{array}$ & $>25 \mathrm{~mm} \mathrm{Hg}$ & 51 & \\
\hline Li and colleagues, ${ }^{34} 2013$ & China & PRS & 26 & $24 \mathrm{mo}$ & EKG, RHC & $>25 \mathrm{~mm} \mathrm{Hg}$ & 45 & 85 \\
\hline $\begin{array}{l}\text { D'Armini and } \\
\text { colleagues, }{ }^{35} 2014\end{array}$ & Italy & RTS & 331 & $49 \mathrm{mo}$ & $\begin{array}{l}\text { V/Q scan, CT, } \\
\text { CTPA }\end{array}$ & $>25 \mathrm{~mm} \mathrm{Hg}$ & 61 & 39 \\
\hline $\begin{array}{l}\text { de Perrot and colleagues, } \\
2015^{37}\end{array}$ & Canada & PRS & 120 & $6 \mathrm{mo}$ & $\begin{array}{l}\text { V/Q scan, EKG, } \\
\text { CTPA, RHC }\end{array}$ & $>25 \mathrm{~mm} \mathrm{Hg}$ & 54 & 53 \\
\hline $\begin{array}{l}\text { Shimura and colleagues, }{ }^{38} \\
2015\end{array}$ & Japan & RTS & 9 & NR & $\begin{array}{l}\text { CT, V/Q scan, } \\
\text { CTPA, ABG, } \\
\text { PFT, EKG }\end{array}$ & 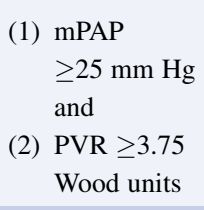 & 54 & 22 \\
\hline $\begin{array}{l}\text { Cannon and colleagues, }{ }^{39} \\
2016\end{array}$ & United Kingdom & PRS & 880 & $4.3 \mathrm{y}$ & V/Q scan, CTPA & $\geq 25 \mathrm{~mm} \mathrm{Hg}$ & 57 & 53 \\
\hline $\begin{array}{l}\text { Jujo and colleagues, }{ }^{36} \\
2016\end{array}$ & Japan & PRS & 17 & $1-2 \mathrm{mo}$ & $\begin{array}{l}\text { RHC, V/Q scan, } \\
\text { CTPA }\end{array}$ & NR & 64 & 29 \\
\hline
\end{tabular}


TABLE 1. Continued

\begin{tabular}{|c|c|c|c|c|c|c|c|c|}
\hline Study & Origin & Design & Subjects & Follow-up & Diagnostic methods & $\begin{array}{c}\text { Criteria for } \\
\text { RPH } \\
\end{array}$ & Age (y) & Male (\%) \\
\hline $\begin{array}{l}\text { Richter and } \\
\text { colleagues, }{ }^{41} 2016\end{array}$ & Germany & PRS & 37 & $1 \mathrm{y}$ & $\begin{array}{c}\text { CXR, EKG, PFT, } \\
\text { ABG, RHC, V/Q } \\
\text { scan, CT, CTPA }\end{array}$ & $\begin{array}{l}>25 \mathrm{~mm} \mathrm{Hg} \text { and } \\
\text { PVR }>240 \\
\quad \text { dyn.s } / \mathrm{cm}^{5}\end{array}$ & 61 & 54 \\
\hline Surie, ${ }^{43} 2016$ & Netherlands & PRS & 55 & NR & $\begin{array}{l}\text { PFT, EKG, V/Q scan, } \\
\text { CTPA }\end{array}$ & $>25 \mathrm{~mm} \mathrm{Hg}$ & 52 & 35 \\
\hline $\begin{array}{l}\text { Nierlich and Ristl, } \\
2016\end{array}$ & Austria & RTS & 161 & NR & $\begin{array}{c}\text { V/Q scan, CT, RHC, } \\
\text { CTPA, US, PFT }\end{array}$ & NR & NR & 61 \\
\hline $\begin{array}{l}\text { Leung and colleagues, }{ }^{42} \\
2016\end{array}$ & Canada & PRS & 38 & 29 & $\begin{array}{l}\text { V/Q scan, CT, RHC, } \\
\text { CTPA, US, PFT }\end{array}$ & $>25 \mathrm{~mm} \mathrm{Hg}$ & 54 & 45 \\
\hline
\end{tabular}

$R P H$, Residual pulmonary hypertension; $R T S$, retrospective; $A B G$, arterial blood gas; $C X R$, chest x-ray; $E K G$, electrocardiogram; $/ Q$, ventilation/perfusion; $C T$, computed tomography; CTPA, computed tomography pulmonary angiography; $N R$, not reported; $P R S$, prospective; $R H C$, right heart catheterization; $P F T$, pulmonary function testing; US, ultrasound. *Song G, Liu Y, Su P-x, Zhai Z-g, Yang Y-h, Wang C. Pulmonary andarterectomy for chronic thromboembolic pulmonary hypertension: preliminary exploration in China. Chin Med J. 2010;123:979-83.

showed that the publication bias was not statistically significant (Figure 3).

\section{Pulmonary Vascular Resistance Before and After Pulmonary Endarterectomy}

Nineteen studies reported change in PVR after PEA in patients with CTPEH. The heterogeneity between these studies was not statistically significant (chi-square 3.53 [df 9]; $\left.\mathrm{I}^{2} 0 \% ; P=.94\right)$. A random effects model showed that PVR decreased by an average of 560.3 dyn.s $/ \mathrm{cm}^{5}$ after PEA (SMD, 1.64; 95\% CI, 1.58-1.70). This reduction was statistically significant $(P<.00001)$ (Figure 4$)$.

The funnel plot showed a likelihood of publication bias, because all the studies were plotted on the right side of the plot. Duvall and Tweedie's trim and fill imputed 8 possibly missing studies. Egger's test of the intercept (B0 4.19; 95\% $\mathrm{CI},-0.00$ to $\left.8.39 ; \mathrm{t}=2.11 ; \mathrm{df}=9 ; P_{1 \text {-tailed }} .33\right)$ showed that the publication bias was not statistically significant (Figure 4).

\section{Six-Minute Walk Distance Before and After Pulmonary Endarterectomy}

Eleven studies reported improvements in 6MWD after PEA in patients with CTPEH. The heterogeneity between these studies was not statistically insignificant (chi-square 6.25 [df 6]; $\mathrm{I}^{2} 4 \% ; P=.40$ ). A random-effects model showed that 6MWD increased by an average of $95.7 \mathrm{~m}$ after PEA (SMD $=-0.83 ; 95 \%$ CI, -0.91 to -0.76 ). This decrease was statistically significant (Figure 5).

The funnel plot showed a likelihood of publication bias, because all the studies were plotted on the right side of the plot. Duvall and Tweedie's trim and fill imputed 2 possibly missing studies. Egger's test of the intercept (B0 0.43; 95\% $\mathrm{CI},-0.52$ to $\left.1.38 ; \mathrm{t}=1.03 ; \mathrm{df}=6 ; P_{1 \text {-tailed }} .17\right)$ showed that the publication bias was not statistically significant (Figure 5).
New York Heart Association/World Health Organization III to IV Clinical Score Before and After Pulmonary Endarterectomy

Six studies reported a significant reduction in the number of patients with New York Heart Association/World Health Organization (WHO) III to IV clinical scores after PEA in patients with CTPEH. The heterogeneity between these studies was statistically significant (chi-square 40.0 [df 5]; $\left.\mathrm{I}^{2}=88 \% ; P<.00001\right)$. The DerSimonian and Laird random effects model indicated that the incidence of patients associated with New York Heart Association/WHO III-IV decreased by an average of 41.2 after PEA (95\% CI, 9.2-184.6). This reduction was statistically significant $(P<.00001)$ (Figure 6). The asymmetry in the funnel plot in Figure 6 (bottom) indicated a likelihood of publication bias, because most of the studies were plotted on the left side of the plot.

\section{DISCUSSION}

This study was conducted to estimate the incidence of RPH after PEA in patients with CTEPH. The methodology was limited to English language publications to reduce publication bias, perhaps at the cost of limiting the generalizability of the findings, despite the meta-analysis including 4686 patients with CTEPH. PEA aims to increase the PVR, improve the ventilation/perfusion, and alleviate right ventricular compromise. Although a curative operation for many, $16.7 \%$ to $35 \%$ patients experience $\mathrm{PH}$ after PEA. ${ }^{3,20,44}$ This persistence is mainly due to the failure to remove distal or chronic thromboemboli or to secondary vascular pathologies. Our analysis provides a similar estimate, because $25 \%$ of patients had RPH after PEA. ${ }^{19}$ Condliffe and colleagues ${ }^{19}$ investigated predictors of outcomes in CTEPH, reporting that approximately $92 \%$ of patients with associated medical conditions experienced RPH, whereas only $20 \%$ of patients who did not have associated medical conditions experienced RPH. In addition, RPH was 
TABLE 2. Outcome characteristics of the included studies

\begin{tabular}{|c|c|c|c|c|c|c|c|c|c|c|}
\hline \multirow[b]{2}{*}{ Study } & \multicolumn{2}{|c|}{ mPAP, mm Hg } & \multicolumn{2}{|c|}{ PVR, dyn.s/cm ${ }^{5}$} & \multicolumn{2}{|c|}{$\begin{array}{c}\text { NYHA/WHO } \\
\text { class III-IV (\%) }\end{array}$} & \multicolumn{2}{|c|}{ 6MWD, m } & \multirow{2}{*}{$\begin{array}{c}\text { Time from } \\
\text { surgery } \\
\text { (mo) }\end{array}$} & \multirow[b]{2}{*}{ RPH, (\%) } \\
\hline & Pre & Post & Pre & Post & Pre & Post & Pre & Post & & \\
\hline $\begin{array}{l}\text { Yin and } \\
\quad \text { colleagues, }{ }^{24} 1992\end{array}$ & $53 \pm 12$ & $17 \pm 6$ & $1045 \pm 430$ & $194 \pm 75$ & 100 & 43 & NR & NR & NR & 3 \\
\hline $\begin{array}{l}\text { D'Armini and } \\
\text { colleagues, }{ }^{25} 2000\end{array}$ & $50 \pm 10$ & $16 \pm 3$ & $1056 \pm 0$ & $182 \pm 15$ & NR & NR & NR & NR & 24 & NR \\
\hline $\begin{array}{l}\text { Nagaya and } \\
\quad \text { colleagues, }{ }^{26} 2002\end{array}$ & $46 \pm 2$ & $19 \pm 1$ & NR & NR & NR & NR & NR & NR & 1 & NR \\
\hline $\begin{array}{l}\text { Zoia and } \\
\text { colleagues, }{ }^{27} 2002\end{array}$ & $50 \pm 12$ & $26 \pm 10$ & $1067 \pm 0$ & $335 \pm 196$ & NR & NR & NR & NR & $3,12,24$ & NR \\
\hline $\begin{array}{l}\text { Ogino and } \\
\quad \text { colleagues, }{ }^{28} 2006\end{array}$ & NR & NR & $1024 \pm 10$ & $320 \pm 215$ & 97 & 1 & NR & NR & 36,60 & 11 \\
\hline $\begin{array}{l}\text { Bonderman and } \\
\text { colleagues, }{ }^{18} 2007^{*}\end{array}$ & $49 \pm 13$ & $25 \pm 12$ & $859 \pm \mathrm{NR}$ & $269 \pm 222$ & 18 & NR & NR & NR & 12,24 & NR \\
\hline $\begin{array}{l}\text { Condliffe and } \\
\text { colleagues, }{ }^{19} 2008\end{array}$ & $48 \pm 11$ & $27 \pm 10$ & $1028 \pm 120$ & $464 \pm 215$ & 88 & 12 & $275 \pm 275$ & $380 \pm 380$ & 12,36 & 35 \\
\hline $\begin{array}{l}\text { Ishida and } \\
\text { colleagues, }{ }^{29} 2009\end{array}$ & $47 \pm 12$ & $25 \pm 10$ & $925 \pm 142$ & $337 \pm 260$ & 60 & 14 & NR & NR & 7,59 & 26 \\
\hline $\begin{array}{l}\text { Song and } \\
\quad \text { colleagues, } \nmid 2010\end{array}$ & $49 \pm 16$ & $27 \pm 11$ & $939 \pm 03$ & $317 \pm 153$ & 100 & 0 & $308 \pm 308$ & $446 \pm 446$ & 12,24 & NR \\
\hline $\begin{array}{l}\text { van der Plas and } \\
\text { colleagues, }{ }^{31} 2010\end{array}$ & $43 \pm 14$ & $25 \pm 8$ & $769 \pm \mathrm{NR}$ & $430 \pm 175$ & NR & NR & $401 \pm 401$ & $506 \pm 506$ & 12 & 32 \\
\hline $\begin{array}{l}\text { Mayer and } \\
\text { colleagues, }{ }^{3} 2011\end{array}$ & NR & NR & $750 \pm 5$ & $247 \pm 10$ & 81 & NR & $366 \pm 366$ & $458 \pm 458$ & 12 & 17 \\
\hline $\begin{array}{l}\text { Freed and } \\
\quad \text { colleagues, }{ }^{20} 2011\end{array}$ & $48 \pm 12$ & $26 \pm 10$ & $805 \pm 0$ & $301 \pm 232$ & & NR & $269 \pm 269$ & $367 \pm 367$ & 3 & 31 \\
\hline $\begin{array}{l}\text { van der Plas and } \\
\text { colleagues, }{ }^{33} 2011 \ddagger\end{array}$ & $44 \pm 11$ & $25 \pm 7$ & $\mathrm{NR} \pm \mathrm{NR}$ & $\mathrm{NR} \pm \mathrm{NR}$ & NR & NR & NR & NR & $24,36,48,60$ & NR \\
\hline $\begin{array}{l}\text { de Perrot and } \\
\text { colleagues, }{ }^{32} 2011\end{array}$ & $45 \pm 10$ & $25 \pm 5$ & $880 \pm 408$ & $320 \pm 70$ & 80 & 40 & $376 \pm 376$ & $480 \pm 480$ & 6,23 & 93 \\
\hline $\begin{array}{l}\text { Madani and } \\
\text { colleagues, }{ }^{15} 2012\end{array}$ & $46 \pm 12$ & $27 \pm 9$ & $790 \pm$ N/A & $274 \pm 176$ & 90 & NR & NR & NR & 60,120 & NR \\
\hline $\begin{array}{l}\mathrm{Li} \text { and } \\
\quad \text { colleagues, }{ }^{34} 2013\end{array}$ & $55 \pm 16$ & $32 \pm 15$ & $944 \pm 484$ & $334 \pm 78$ & 78 & 48 & NR & NR & $3,12,24$ & 5 \\
\hline $\begin{array}{l}\text { D'Armini and } \\
\text { colleagues, }{ }^{35} 2014\end{array}$ & $45 \pm 11$ & $23 \pm 7$ & $901 \pm 00$ & $273 \pm 154$ & 87 & 0 & $283 \pm 283$ & $395 \pm 395$ & 3,12 & 5 \\
\hline $\begin{array}{l}\text { de Perrot and } \\
\text { colleagues, }{ }^{37} 2015\end{array}$ & $44 \pm 13$ & $25 \pm 12$ & $841 \pm 4$ & NR & 91 & & $365 \pm 365$ & $430 \pm 430$ & 20,60 & 38 \\
\hline $\begin{array}{l}\text { Shimura and } \\
\text { colleagues, }{ }^{38} 2015\end{array}$ & $50 \pm 5$ & $34 \pm 3$ & NR & NR & 100 & 22 & NR & NR & 6,12 & 100 \\
\hline $\begin{array}{l}\text { Cannon and } \\
\text { colleagues, }{ }^{39} 2016\end{array}$ & $47 \pm 11$ & $27 \pm 10$ & $830 \pm N R 3$ & $317 \pm 239$ & NR & NR & $260 \pm 260$ & $353 \pm 353$ & $3,6,12$ & NR \\
\hline $\begin{array}{l}\text { Jujo and } \\
\text { colleagues, }{ }^{36} 2016\end{array}$ & $45 \pm 11$ & $26 \pm 10$ & $725 \pm 2$ & $319 \pm 170$ & NR & NR & NR & NR & 12 & NR \\
\hline $\begin{array}{l}\text { Richter and } \\
\text { colleagues, }{ }^{41} 2016\end{array}$ & $43 \pm 9$ & $29 \pm 8$ & $606 \pm 220$ & $328 \pm 241$ & 73 & 22 & $405 \pm 405$ & $453 \pm 453$ & 12 & 57 \\
\hline Surie, ${ }^{43} 2016$ & $42 \pm 14$ & $24 \pm 7$ & $644 \pm 4$ & NR & 87 & & $397 \pm 397$ & $497 \pm 497$ & 3,12 & NR \\
\hline $\begin{array}{l}\text { Nierlich and Ristl, }{ }^{40} \\
2016\end{array}$ & $50 \pm 13$ & $32 \pm 10$ & $794 \pm 9$ & $303 \pm 171$ & NR & NR & NR & NR & 2,6 & NR \\
\hline
\end{tabular}




\begin{tabular}{|c|c|c|c|c|c|c|c|c|c|c|}
\hline \multirow[b]{2}{*}{ Study } & \multicolumn{2}{|c|}{ mPAP, mm Hg } & \multicolumn{2}{|c|}{ PVR, dyn.s $/ \mathrm{cm}^{5}$} & \multicolumn{2}{|c|}{$\begin{array}{l}\text { NYHA/WHO } \\
\text { class III-IV (\%) }\end{array}$} & \multicolumn{2}{|c|}{ 6MWD, m } & \multirow{2}{*}{$\begin{array}{c}\text { Time from } \\
\text { surgery } \\
\text { (mo) }\end{array}$} & \multirow[b]{2}{*}{ RPH, (\%) } \\
\hline & Pre & Post & Pre & Post & Pre & Post & Pre & Post & & \\
\hline $\begin{array}{l}\text { Leung and } \\
\text { colleagues, }{ }^{42} 2016\end{array}$ & $50 \pm 14$ & $32 \pm 7$ & $1209 \pm 132$ & 500 (11 patients) & 97 & 13 & $\mathrm{NR}$ & NR & $6,24,36,48$ & 8 \\
\hline
\end{tabular}

reported in $35 \%$ of patients after PEA in a British study. ${ }^{45}$ The increased morbidity and mortality associated with RPH were historically a significant problem; however, the overall perioperative mortality rate decreased from $27 \%$ between 1992 and 1995 to $15 \%$ between 1996 and 1999 and has been at $5 \%$ since $2004 .^{18}$

Successful PEA surgery can result in near complete normalization of pulmonary hemodynamics, with immediate reductions seen in both $\mathrm{MPAP}$ and PVR and increases in 6MWD. The changes in mPAP, PVR, and 6MWD were quantified using a pooled estimate meta-analysis, mPAP and PVR of particular note because they are good predictors of postoperative hospital mortality in patients with CTEPH. $^{46}$

mPAP was reduced after PEA by approximately $21 \mathrm{~mm}$ $\mathrm{Hg}(\mathrm{SMD}=1.75 ; 95 \% \mathrm{CI},-1.62$ to $1.88 ; P<.00001)$.
Large-scale studies have shown that a postoperative mPAP of greater than $46 \mathrm{~mm} \mathrm{Hg}$ increases the probability of in-hospital mortality. Thus, an mPAP of 46 to $50 \mathrm{~mm}$ $\mathrm{Hg}$ has been considered a cutoff between high- and lowrisk patients. ${ }^{46,47}$ Historically, the 3-year survival for patients with an mPAP of greater than $30 \mathrm{~mm} \mathrm{Hg}$ was as low as $10 \% .{ }^{10}$ However, the use of disease-modifying treatments such as bosentan has greatly increased post-PEA survival, with a 1-year survival of $96 \%$ achieved with bosentan in patients with persistent $\mathrm{PH}$ even with an mPAP of $51 \mathrm{~mm}$ $\mathrm{Hg}^{48}$

The average pooled estimate of reduction in PVR after PEA was 561 dyn.s $/ \mathrm{cm}^{5}$ (SMD $=1.64 ; 95 \%$ CI, 1.581.70), from 883 dyn.s $/ \mathrm{cm}^{5}$ presurgery to 309 dyn.s $/ \mathrm{cm}^{5}$ postsurgery. A preoperative PVR greater than 1000 to 1150 dyn.s $/ \mathrm{cm}^{5}$ increased hospital postoperative mortality,

\begin{tabular}{|c|c|c|c|c|}
\hline & $\begin{array}{c}\text { Event } \\
\text { rate }\end{array}$ & $\begin{array}{c}\text { Lower } \\
\text { limit }\end{array}$ & $\begin{array}{l}\text { Upper } \\
\text { limit }\end{array}$ & $\begin{array}{r}\text { Relative } \\
\text { weight }\end{array}$ \\
\hline Yin et al, 1992 & 0.03 & 0.00 & 0.19 & 2.72 \\
\hline Nagaya et al, 2002 & 0.32 & 0.19 & 0.50 & 5.73 \\
\hline Ogino et al, 2006 & 0.11 & 0.06 & 0.20 & 5.89 \\
\hline Bonderman et al, 2007 & 0.22 & 0.15 & 0.31 & 6.35 \\
\hline Condliffe et al, 2008 & 0.35 & 0.29 & 0.41 & 6.69 \\
\hline Ishida et al, 2009 & 0.26 & 0.12 & 0.47 & 5.15 \\
\hline van der Plas et al, 2010 & 0.31 & 0.21 & 0.45 & 6.10 \\
\hline Mayer et al, 2011 & 0.17 & 0.13 & 0.21 & 6.69 \\
\hline Freed et al, 2011 & 0.31 & 0.26 & 0.36 & 6.73 \\
\hline van der Plas et al, 2011 & 0.31 & 0.23 & 0.41 & 6.41 \\
\hline Li et al., 2013 & 0.08 & 0.02 & 0.26 & 3.81 \\
\hline D'Armini et al., 2014 & 0.05 & 0.03 & 0.07 & 6.23 \\
\hline Perrot et al, 2015 & 0.38 & 0.29 & 0.46 & 6.53 \\
\hline Shimura et al, 2015 & 0.95 & 0.53 & 1.00 & 1.67 \\
\hline Cannon et al, 2016 & 0.51 & 0.48 & 0.54 & 6.83 \\
\hline Richter et al, 2016 & 0.57 & 0.41 & 0.72 & 5.91 \\
\hline Surie, 2016 & 0.31 & 0.20 & 0.44 & 6.10 \\
\hline \multirow[t]{2}{*}{ Sang et al., 2016} & 0.08 & 0.03 & 0.22 & 4.47 \\
\hline & 0.25 & 0.18 & 0.34 & \\
\hline
\end{tabular}

FIGURE 2. Forest plot of residual PH after PEA in patients with CTPEH. Pooled event rates are estimated with a random effects model, which shows that $25 \%$ (95\% CI, 0.18-0.34) of the patients experienced RPH after PEA. 


\begin{tabular}{lrr} 
& \multicolumn{2}{c}{ mPAP (mmHg) Pre-o } \\
Study or Subgroup & Mean & SD \\
\hline Bonderman et al. 2007 & 49.3 & 13.02 \\
Cannon et al. 2016 & 47 & 11 \\
Condliffe et al. 2008 & 48 & 11 \\
D'Armini et al. 2000 & 50 & 10 \\
D'Armini et al. 2014 & 45 & 10.5 \\
de Perrot et al. 2011 & 45 & 10 \\
Freed et al. 2011 & 48 & 12 \\
Ishida et al. 2009 & 47 & 12 \\
Jujo et al. 2016 & 44.6 & 11.2 \\
Li et al. 2013 & 54.7 & 16 \\
Madani et al. 2012 & 45.8 & 11.5 \\
Nagaya et al. 2002 & 46 & 2 \\
Nierlich and Ristl, 2016 & 49.72 & 13.05 \\
Perrot et al. 2015 & 44.28 & 13.05 \\
Richter et al. 2016 & 43.2 & 8.7 \\
Sang et al. 2016 & 49.9 & 14.2 \\
Shimura et al. 2015 & 49.86 & 5.04 \\
Song et al. 2010 & 49.4 & 16 \\
Surie 2016 & 42 & 14 \\
van der Plas et al. 2010 & 43 & 14 \\
van der Plas et al. 2011 & 43.7 & 10.9 \\
Yi 1992 & 53 & 12 \\
Zoia et al. 2002 & 50 & 12 \\
& &
\end{tabular}

\begin{tabular}{llr} 
& \multicolumn{3}{c}{ mPAP $(\mathrm{mmHg})$ Post-o } \\
\hline 105 & 25.46 & 12.47
\end{tabular}

$\begin{array}{lllll}105 & 25.46 & 12.47 & 105 & 13.0 \%\end{array}$

27

$236 \quad 27$

$33 \quad 16$

331
58

314

23

23
17
26

$26 \quad 31$.

$1500 \quad 27.35$

$34 \quad 19$

$161 \quad 31.72$

$120 \quad 25.45$

$37 \quad 28.9$

$38 \quad 32$

34.25

26.8

24

25
24.6
17

26
10

3

6.5

6.5
5

10

10

10.1

14.6

9.25

1
10.27

10.27

11.76

8.1
7.3

2.59

10.5

7
8

7.2

6
$236 \quad 22.5 \%$

$33 \quad 0.0 \%$

$58 \quad 0.0 \%$

$314 \quad 0.0 \%$

$23 \quad 3.3 \%$

$17 \quad 2.6 \%$

$26 \quad 4.2 \%$

$1500 \quad 0.0 \%$

$34 \quad 0.0 \%$

$161 \quad 19.3 \%$

$120 \quad 0.0 \%$

$37 \quad 5.6 \%$

$38 \quad 5.9 \%$

$9 \quad 0.0 \%$

$15 \quad 2.4 \%$

$55 \quad 8.1 \%$

$54 \quad 8.1 \%$

$96 \quad 0.0 \%$

$32 \quad 0.0 \%$

$38 \quad 4.9 \%$

Total $(95 \% \mathrm{Cl})$

805

Heterogeneity: $\mathrm{Tau}^{2}=0.01 ; \mathrm{Chi}^{2}=12.80, \mathrm{df}=11(\mathrm{P}=0.31) ; \mathrm{I}^{2}=14 \%$

Test for overall effect: $Z=25.91(P<0.00001)$

Std. Mean Difference

IV, Random, $95 \%$ C

CI IV, Random, $95 \% \mathrm{Cl}$

$1.86[1.54,2.19]$

$1.90[1.79,2.01]$

$1.99[1.77,2.22]$

$4.55[3.62,5.49]$

$2.52[2.31,2.72]$

2.51 [2.02, 3.00]

$1.99[1.80,2.18]$

$1.96[1.24,2.67]$

$1.68[0.88,2.47]$

$1.49[0.87,2.10]$

$1.77[1.68,1.85]$

$16.88[13.92,19.84]$

$1.53[1.28,1.78]$

$1.51[1.22,1.80]$

$1.68[1.15,2.22]$

$1.57[1.05,2.09]$

$3.71[2.06,5.36]$

$1.62[0.78,2.47]$

$1.61[1.18,2.05]$

$1.57[1.13,2.00]$

$2.06[1.71,2.41]$

$3.75[2.92,4.58]$

$2.15[1.58,2.72]$

$805 \quad 100.0 \%$

$1.75[1.62,1.88]$

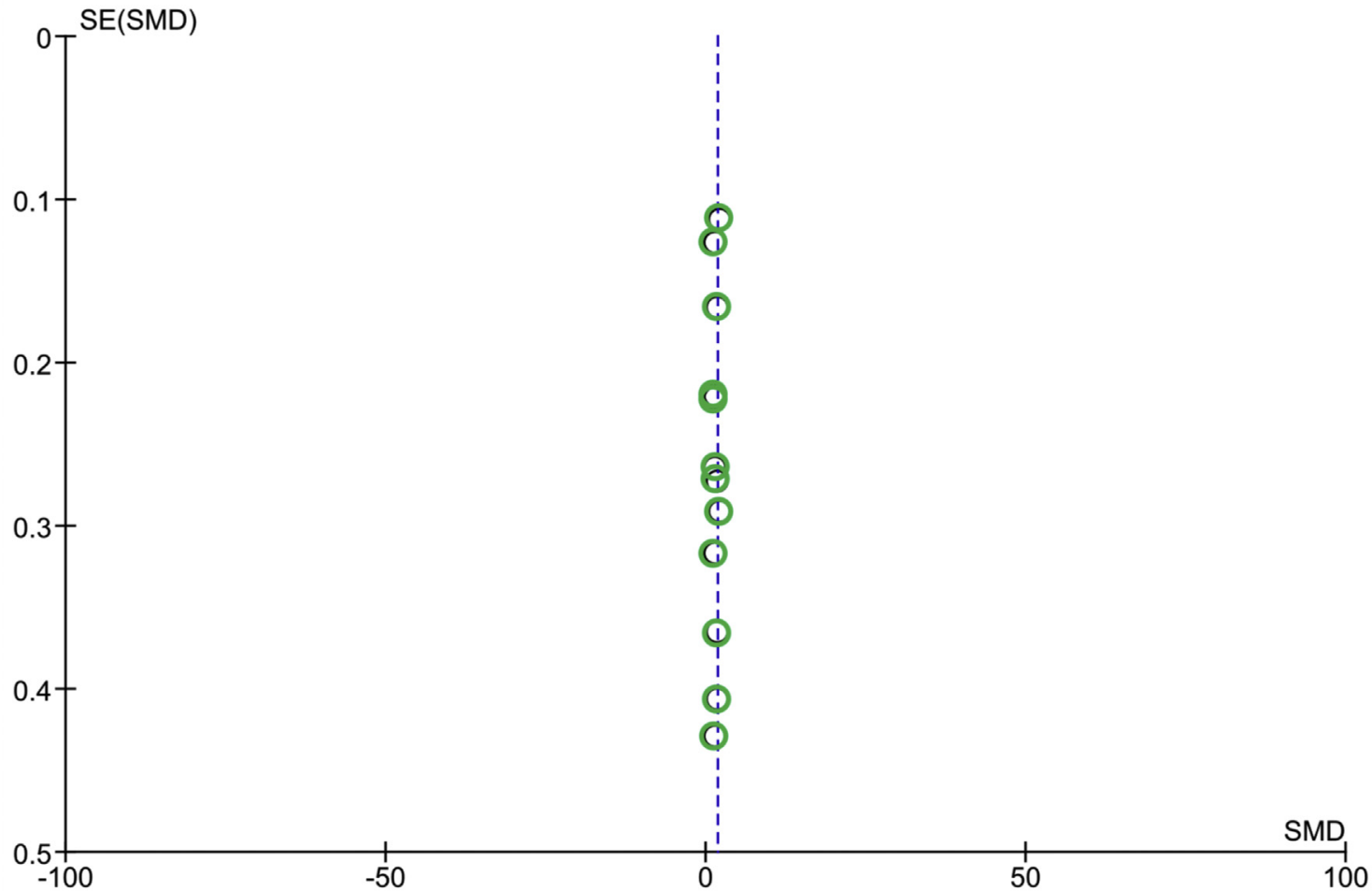

FIGURE 3. Forest (top) and funnel (bottom) plot of standardized mean difference in mPAP in patients with CTEPH pre- and post-PEA. Standardized mean differences are estimated with a random effects model, which shows that $\mathrm{mPAP}$ decreased by an average of $21.42 \mathrm{~mm} \mathrm{Hg}$ after PEA $(\mathrm{SMD}=1.75 ; 95 \% \mathrm{CI}$, $1.62-1.88 ; P<.00001)$. The funnel plot shows a likelihood of publication bias, as all the studies are plotted on the right side of the plot, although this was not statistically significant by Egger's test of the intercept $\left(\mathrm{B}_{0}-0.74 ; 95 \% \mathrm{CI},-3.85\right.$ to $\left.2.37 ; \mathrm{t}=0.49 ; \mathrm{df}=11 ; P_{1 \text {-tailed }} 0.31\right)$. $m P A P, \mathrm{Mean}$ pulmonary artery pressure; $S D$, standard deviation; $C I$, confidence interval; $S E$, standard error; $S M D$, standardized mean difference.

with a PVR of 645 dyn.s $/ \mathrm{cm}^{5}$ considered a preoperative cutoff between high- and low-risk patients. ${ }^{46}$ Intervention with PEA typically will demonstrate a reduction in PVR of approximately 400 to $500 \mathrm{dyn} . \mathrm{s} / \mathrm{cm}^{5}$. Although preoperative high PVR is an important risk factor, postoperative PVR is more strongly linked to in-hospital mortality. 


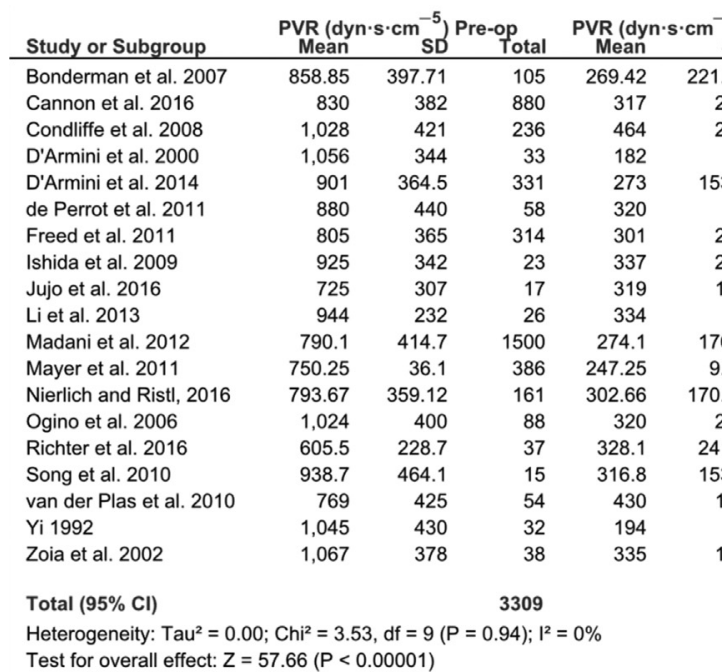
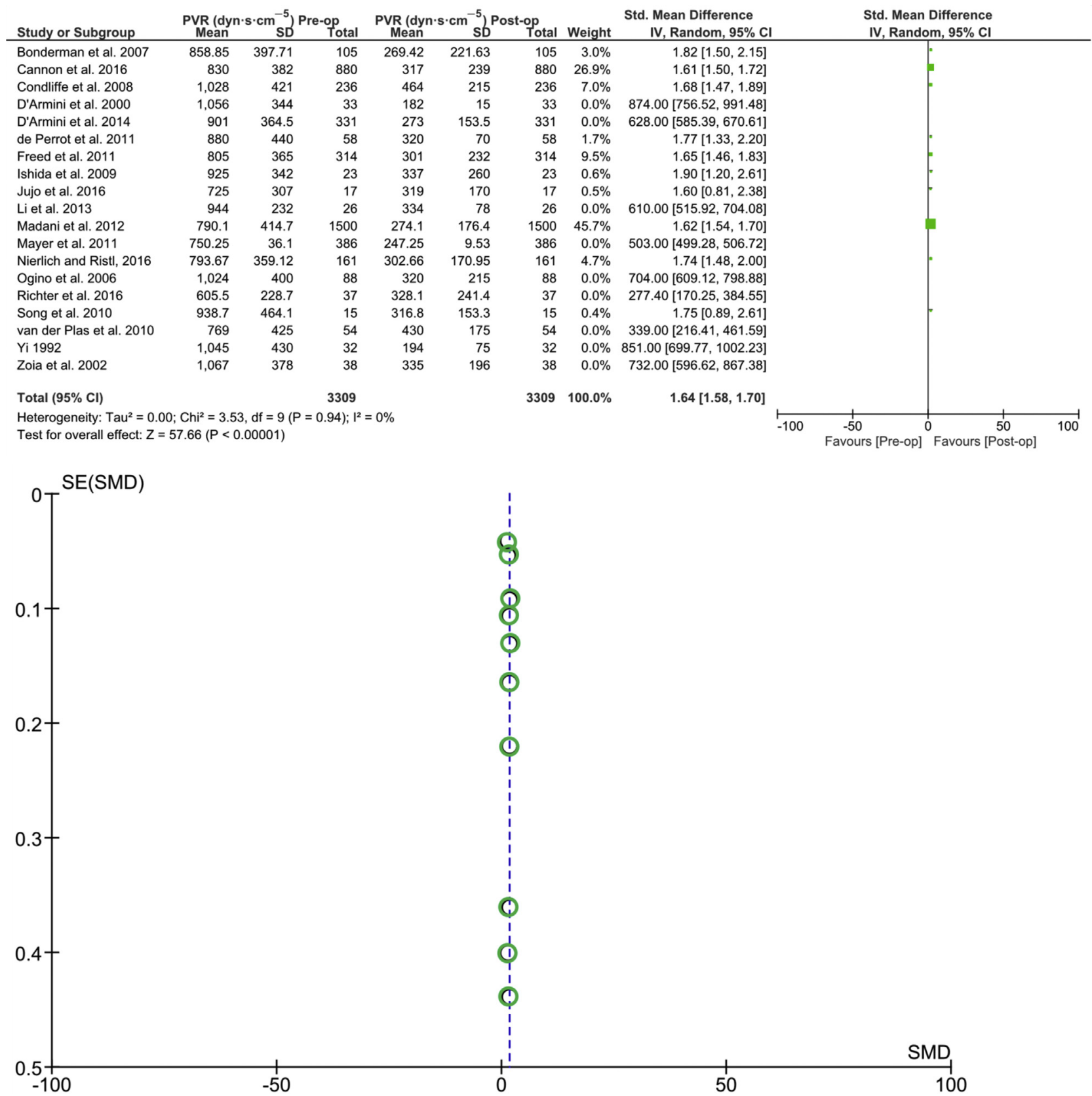

FIGURE 4. Forest (top) and funnel (bottom) plot of standardized mean difference of PVR in patients with CTEPH pre- and post-PEA. Raw differences in means are estimated with a random effects model, which shows that PVR reduced by an average of $560.3 \mathrm{dyn} . \mathrm{s} / \mathrm{cm}^{5}$ after PEA (SMD $=1.64 ; 95 \%$ CI, 1.58 $1.70 ; P<.00001)$. The funnel plot shows a likelihood of publication bias, as all the studies are plotted on the right side of the plot, although this was not statistically significant by Egger's test of the intercept $\left(\mathrm{B}_{0} 4.19 ; 95 \% \mathrm{CI},-0.00\right.$ to $\left.8.39 ; \mathrm{t}=2.11 ; \mathrm{df}=9 ; P_{1 \text {-tailed }} 0.33\right)$. $P V R$, Pulmonary vascular resistance; $S D$, standard deviation; $C I$, confidence interval; $S E$, standard error; $S M D$, standardized mean difference.

Mortality rates were reported as $4 \%$ for patients with PVR less than 900 dyn.s $/ \mathrm{cm}^{5}, 10 \%$ for patients with a PVR between 900 and 1200 dyn.s $/ \mathrm{cm}^{5}$, and $20 \%$ for patients with a PVR greater than 1200 dyn.s $/ \mathrm{cm}^{5} .{ }^{12}$ Our meta-analysis suggests that PEA drastically reduces the PVR. The reduction in PEA may increase the survival of patients.

The 6MWD is a useful test to assess functional outcome after PEA and is reported to correlate with the hemodynamic severity of the disease. ${ }^{33}$ The pooled average increase in 6MWD was $96 \mathrm{~m}$, from $337 \mathrm{~m}$ presurgery to $433 \mathrm{~m}$ after surgery.

Until recently, there were no approved treatments for inoperable CTEPH or for patients with persistent $\mathrm{PH}$. Instead, PAH-specific pharmacologic agents were used off-label. These drugs demonstrated variable clinical efficacy and included inhaled iloprost, epoprostenol, 


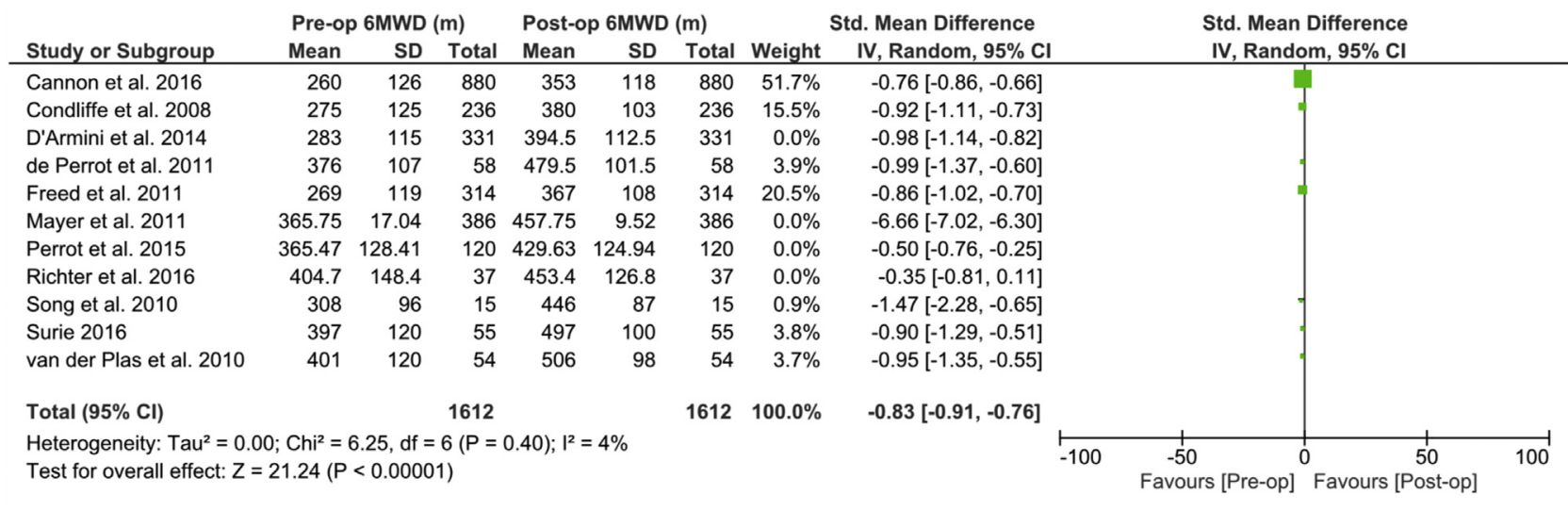

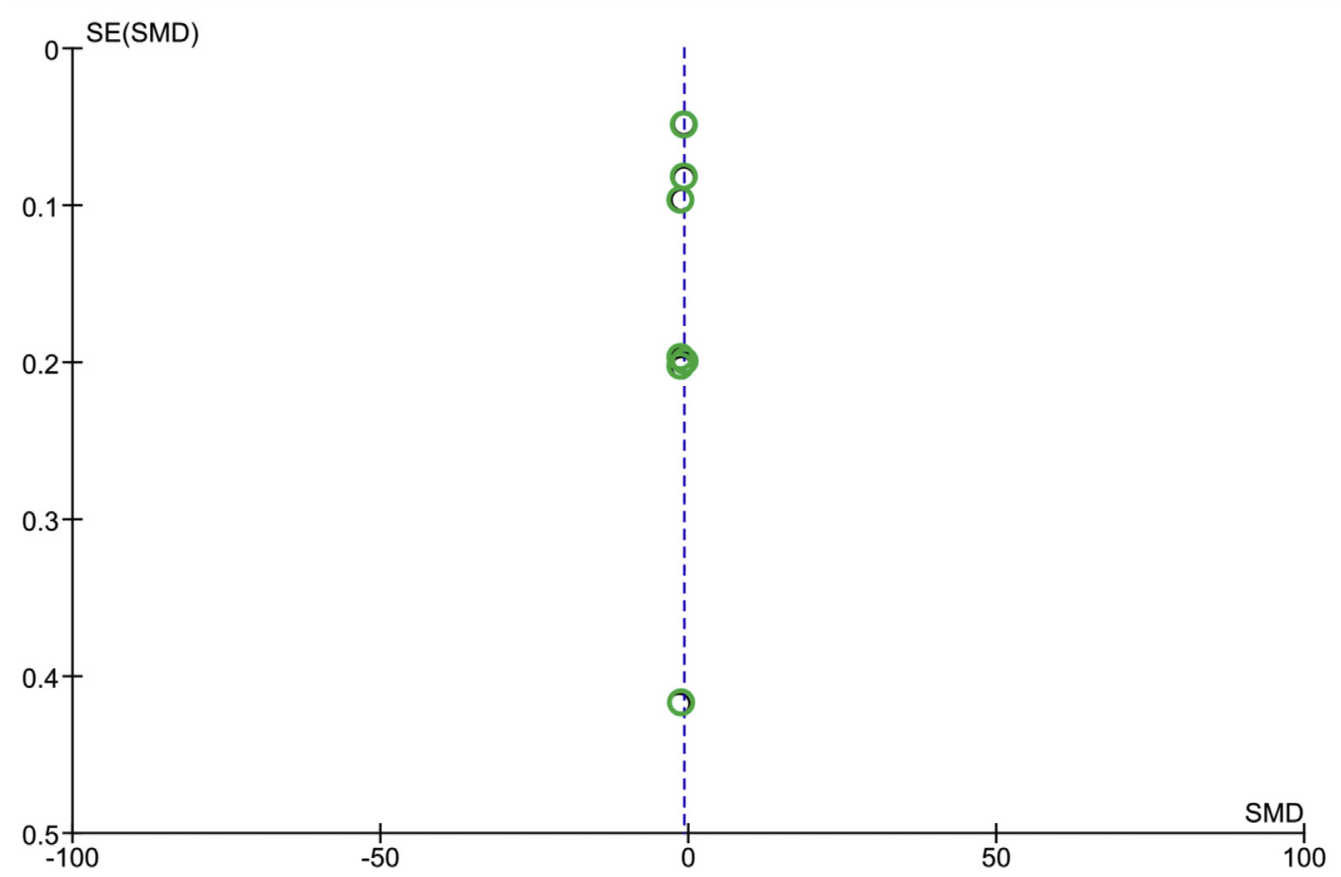

FIGURE 5. Forest (top) and funnel (bottom) plot of mean difference in 6MWD in patients with CTEPH in pre- and post-PEA. Raw difference in means is estimated with a random effects model, which shows that 6MWD increased by an average of $95.7 \mathrm{~m}$ after PEA (SMD $=-0.83 ; 95 \%$ CI, -0.91 to -0.76 ; $P<.00001)$. The funnel plot shows a likelihood of publication bias, as all the studies are plotted on the right side of the plot, although this was not statistically significant by Egger's test of the intercept (B0 0.43; $95 \% \mathrm{CI},-0.52$ to 1.38; $\mathrm{t}=1.03 ; \mathrm{df}=6$; P1-tailed 0.17). 6MWD, 6-minute walk distance; SD, standard deviation; $C I$, confidence interval; $S E$, standard error; $S M D$, standardized mean difference.

treprostinil, sildenafil, and bosentan. ${ }^{44,48-50}$ Recently, riociguat, a soluble guanylate cyclase stimulator, was approved by the US Food and Drug Administration for the treatment of RPH and inoperable CTEPH. Riociguat improves a range of hemodynamic parameters in both inoperable patients and patients post-PEA surgery with persistent $\mathrm{PH}$, as supported by findings from recent clinical trials. ${ }^{51-53}$ Riociguat provides a similar benefit to PEA in inoperable patients with CTEPH by improving PVR but not 6MWD. ${ }^{33,49,50}$ Although a promising therapy, riociguat does not remove the obstructive lesions, and its clinical benefit has not been ascertained in asymptomatic patients with $\mathrm{RPH}^{51}$ As such, balloon pulmonary angioplasty represents an additional treatment option that uses telescoping catheters, wires, and balloons to mechanically disturb chronic clot material. The efficacy of riociguat versus balloon pulmonary angioplasty as a therapy for nonoperable CTEPH has not been reported; however, a clinical trial investigating precisely this is currently under way (Clinicaltrial.gov NCT02634203). Although balloon pulmonary angioplasty seems to improve pulmonary hemodynamics in inoperable, symptomatic patients with CTEPH, further randomized controlled trials are needed to ascertain its clinical benefit. ${ }^{53}$ There is currently no guideline on the optimal medical management of patients with CTEPH undergoing PEA to treat persistent $\mathrm{PH} .{ }^{52}$ If completed, the results from this study will aid in the correct management of patients with persistent $\mathrm{PH}$ and inoperable CTEPH. 


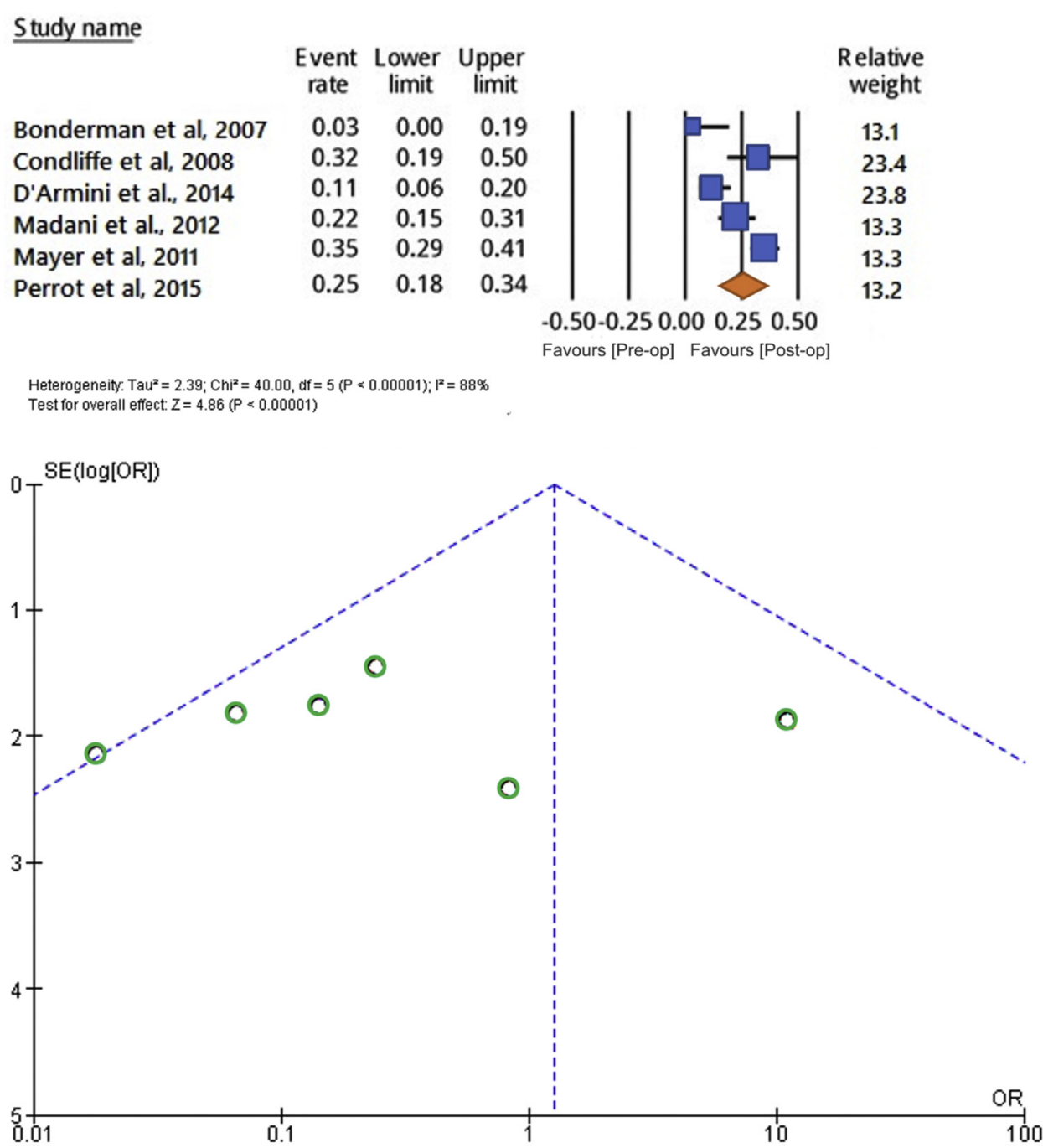

FIGURE 6. Forest (top) and funnel (bottom) plot of New York Heart Association/WHO III-IV clinical scores in patients with CTEPH pre- and post-PEA. Pooled event rates are estimated with a random effects model, which shows that the incidence of patients associated with New York Heart Association/WHO III-IV decreased by an average of 41.2 after PEA $(95 \%$ CI, 9.2-184.6; $P<.00001)$. The asymmetry in the funnel plot indicates a likelihood of publication bias, as most of the studies were plotted on the left side of the plot. $S E$, Standard error.

Recent findings demonstrate the effectiveness of novel pharmacologic treatments, including macitentan ${ }^{54,55}$ and subcutaneous treprostinil, ${ }^{56,57}$ in inoperable patients with CTEPH and patients with RPH in addition to PEA. Of note, a large randomized placebo-controlled clinical trial ("MERIT-1" strated that the use of macitentan led to a significant improvement in PVR in patients with inoperable CTEPH $(\mathrm{n}=80)$.

Lang and colleagues ${ }^{56}$ analyzed clinical outcomes from long-term subcutaneous therapy using treprostinil and found that it improved exercise capacity, hemodynamics, and symptoms in patients with inoperable CTEPH $(\mathrm{n}=23)$, as well as contributing to increasing their longterm survival. ${ }^{57}$ Skoro-Sajer and colleagues ${ }^{57}$ confirmed these findings in patients with severe inoperable CTEPH $(\mathrm{n}=56)$. Short-term venoarterial extracorporeal membrane oxygenation has been suggested as an additional strategy for the treatment of hemorrhage during PEA. ${ }^{58-60}$

One of the largest studies included in this article provided a detailed analysis of long-term follow-up in 198 patients with CTEPH who survived PEA. ${ }^{19}$ Data from this study provided a clear picture of outcomes after PEA. Of the $81 \%$ who survived PEA, $35 \%$ were diagnosed with persistent $\mathrm{PH}$. These patients had a significantly higher mPAP $(50.5 \pm 9.4 \mathrm{~mm} \mathrm{Hg}$ vs $46.5 \pm 10.4 \mathrm{~mm} \mathrm{Hg})$ and PVR $\left(1144 \pm 475\right.$ dyn.s/cm ${ }^{5}$ vs $934 \pm 344$ dyn.s $\left./ \mathrm{cm}^{5}\right)$ scores compared with those showing recovery. The 1-year $(98 \%$ vs $99 \%$ ) and 3-year (94\% vs $93 \%$ ) survivals were comparable between recovered and persistent $\mathrm{PH}$ groups. Patients with persistent $\mathrm{PH}$ also showed improvements in terms of the proportion of WHO class I or II subjects, which 


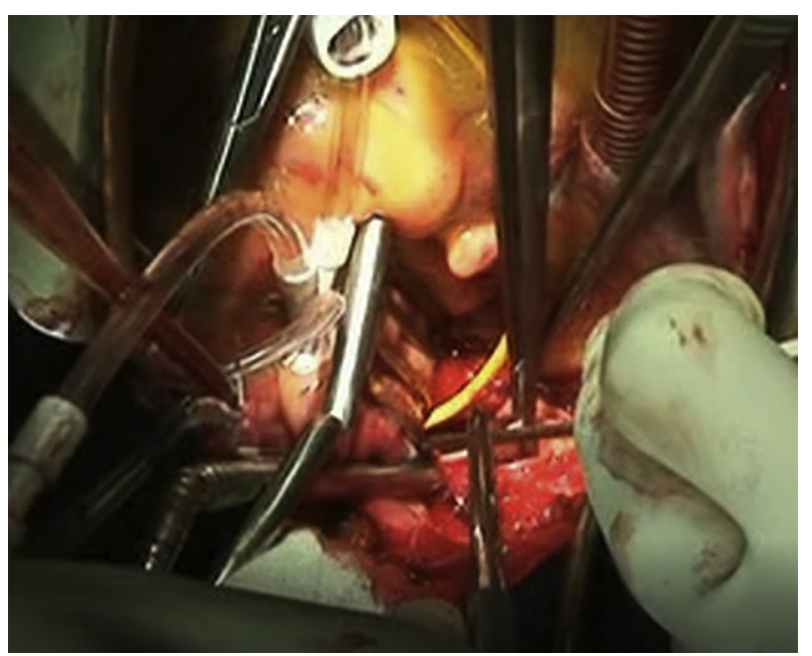

VIDEO 1. Pulmonary endarterectomy. Video available at: https://www. jtcvs.org/article/S0022-5223(18)31258-3/fulltext.

increased from $4 \%$ at baseline to $82 \%$ at 3 months postsurgery. However, the proportion of patients receiving disease-modifying agents increased from $8 \%$ at 3 months to $18 \%$ at 2 years after surgery.

\section{Study Limitations}

The main limitation of this study lies in having assessed only findings from nonrandomized trials because of the lack of relevant data reported in the literature. Other limitations, as discussed in the Materials and Methods section, included the exclusion of gray literature and non-English studies, which might have led to discarding potentially relevant data and that, therefore, might have reduced the heterogeneity in the results. Moreover, the lack of a standardized definition of residual PH further contributes to impair the generalizability of the results. However, the results obtained in this study could be useful to help treat patients with residual PH if assessed similarly to the centers from the studies included in this meta-analysis.

Our analysis shows that a quarter of patients with CTEPH experience persistent PH after PEA. However, PEA provides drastic improvements in hemodynamic and exercise function (Video 1). The literature shows that, despite the high persistence of PH, PEA remains the best available option in patients with CTEPH.

\section{CONCLUSIONS}

Outcomes for patients with CTEPH have greatly improved over the last 20 years. PEA is still the treatment of choice in terms of both survival and functional improvements; however, patients with persistent PH after PEA are now also reported to have a good prognosis. In the current meta-analysis, RPH was reported in $25 \%$ of patients with CTEPH post-PEA surgery. In addition, PEA was seen to significantly reduce hemodynamic parameters and improve the functional outcome as measured by an increase in 6MWD. Accurate diagnosis and assessment by experienced surgical staff are vital for the management of this disorder. For patients ineligible for surgery or with significant postPEA RPH, riociguat and balloon pulmonary angioplasty represent viable therapeutic alternatives for symptomatic patients with RPH.

\section{Conflict of Interest Statement}

Authors have nothing to disclose with regard to commercial support.

\section{References}

1. Fedullo PF, Auger WR, Kerr KM, Rubin LJ. Chronic thromboembolic pulmonary hypertension. $N$ Engl J Med. 2001;345:1465-72.

2. Lang I, Meyer BC, Ogo T, Matsubara H, Kurzyna M, Ghofrani HA, et al. Balloon pulmonary angioplasty in chronic thromboembolic pulmonary hypertension. Eur Respir Rev. 2017;26.

3. Mayer E, Jenkins D, Lindner J, D’Armini A, Kloek J, Meyns B, et al. Surgical management and outcome of patients with chronic thromboembolic pulmonary hypertension: results from an international prospective registry. J Thorac Cardiovasc Surg. 2011;141:702-10.

4. Ende-Verhaar YM, Cannegieter SC, Noordegraaf AV, Delcroix M, Pruszczyk P, Mairuhu AT, et al. Incidence of chronic thromboembolic pulmonary hypertension after acute pulmonary embolism: a contemporary view of the published literature. Eur Respir J. 2017;49.

5. Pepke-Zaba J, Delcroix M, Lang I, Mayer E, Jansa P, Ambroz D, et al. Chronic thromboembolic pulmonary hypertension $(\mathrm{CTEPH})$ clinical perspective: results from an international prospective registry. Circulation. 2011;124:1973-81.

6. Lang IM, Pesavento R, Bonderman D, Yuan XZ. Risk factors and basic mechanisms of chronic thromboembolic pulmonary hypertension: a current understanding. Eur Respir J. 2013;41:462-8.

7. Mehta S, Helmersen D, Provencher S, Hirani N, Rubens FD, De Perrot M, et al. Diagnostic evaluation and management of chronic thromboembolic pulmonary hypertension: a clinical practice guideline. Can Respir J. 2010;17:301-34.

8. Galiè N, Humbert M, Vachiery JL, Gibbs S, Lang I, Torbicki A, et al. 2015 ESC/ ERS guidelines for the diagnosis and treatment of pulmonary hypertension: the joint task force for the diagnosis and treatment of pulmonary hypertension of the European Society of Cardiology (ESC) and the European Respiratory Society (ERS): endorsed by: Association for European Paediatric and Congenital Cardiology (AEPC), International Society for Heart and Lung Transplantation (ISHLT). Eur Heart J. 2015;37:67-119.

9. Riedel M, Stanek V, Widimsky J, Prerovsky I. Long-term follow-up of patients with pulmonary thromboembolism: late prognosis and evolution of hemodynamic and respiratory data. Chest. 1982;81:151-8.

10. Lewczuk J, Piszko P, Jagas J, Porada A, Sobkowicz B, Wrabec K, et al. Prognostic factors in medically treated patients with chronic pulmonary embolism. Chest. 2001;119:818-23.

11. McNeil K, Dunning J. Chronic thromboembolic pulmonary hypertension (CTEPH). Heart. 2007;93:1152-8.

12. Dartevelle P, Fadel E, Mussot S, Chapelier A, Herve P, De Perrot M, et al. Chronic thromboembolic pulmonary hypertension. Eur Respir J. 2004;23: 637-48.

13. Mayer E. Surgical and post-operative treatment of chronic thromboembolic pulmonary hypertension. Eur Respir Rev. 2010;19:64-7.

14. Ozsu S, Cinarka H. Chronic thromboembolic pulmonary hypertension: medical treatment. Pulm Circ. 2013;3:341-4.

15. Madani MM, Auger WR, Pretorius V, Sakakibara N, Kerr KM, Kim NH, et al. Pulmonary endarterectomy: recent changes in a single institution's experience of more than 2,700 patients. Ann Thorac Surg. 2012;94:97-103.

16. Kim NH, Fesler P, Channick RN, Knowlton KU, Ben-Yehuda O, Lee SH, et al. Preoperative partitioning of pulmonary vascular resistance correlates with early outcome after thromboendarterectomy for chronic thromboembolic pulmonary hypertension. Circulation. 2004;109:18-22.

17. Thistlethwaite PA, Kemp A, Du L, Madani MM, Jamieson SW. Outcomes of pulmonary endarterectomy for treatment of extreme thromboembolic pulmonary hypertension. J Thorac Cardiovasc Surg. 2006;131:307-13. 
18. Bonderman D, Skoro-Sajer N, Jakowitsch J, Adlbrecht C, Dunkler D, Taghavi S, et al. Predictors of outcome in chronic thromboembolic pulmonary hypertension. Circulation. 2007;115:2153-8.

19. Condliffe R, Kiely DG, Gibbs JS, Corris PA, Peacock AJ, Jenkins DP, et al. Improved outcomes in medically and surgically treated chronic thromboembolic pulmonary hypertension. Am J Respir Crit Care Med. 2008; 177:1122-7.

20. Freed DH, Thomson BM, Berman M, Tsui SS, Dunning J, Sheares KK, et al. Survival after pulmonary thromboendarterectomy: effect of residual pulmonary hypertension. J Thorac Cardiovasc Surg. 2011;141:383-7.

21. Moser KM, Braunwald NS. Successful surgical intervention in severe chronic thromboembolic pulmonary hypertension. Chest. 1973;64:29-35.

22. Hedges LV. Distribution theory for Glass's estimator of effect size and related estimators. J Educ Stat. 1981;6:107-28.

23. DerSimonian R, Laird N. Meta-analysis in clinical trials. Control Clin Trials. 1986; 7:177-88

24. Yin B, Iversen S, Oelert H. Pulmonary thromboendarterectomy for chronic thromboembolic pulmonary hypertension: the experience of the University Hospital of Mainz. Chin Circ J. 1992;7:312-4.

25. D'Armini AM, Cattadori B, Monterosso C, Klersy C, Emmi V, Piovella F, et al. Pulmonary thromboendarterectomy in patients with chronic thromboembolic pulmonary hypertension: hemodynamic characteristics and changes. Eur J Cardiothorac Surg. 2000;18:696-702.

26. Nagaya N, Ando M, Oya H, Ohkita Y, Kyotani S, Sakamaki F, et al. Plasma brain natriuretic peptide as a noninvasive marker for efficacy of pulmonary thromboendarterectomy. Ann Thorac Surg. 2002;74:180-4.

27. Zoia MC, D'armini AM, Beccaria M, Corsico A, Fulgoni P, Klersy C, et al. Mid term effects of pulmonary thromboendarterectomy on clinical and cardiopulmonary function status. Thorax. 2002;57:608-12.

28. Ogino H, Ando M, Matsuda H, Minatoya K, Sasaki H, Nakanishi N, et al. Japanese single-center experience of surgery for chronic thromboembolic pulmonary hypertension. Ann Thorac Surg. 2006;82:630-6.

29. Ishida K, Masuda M, Tanaka H, Imamaki M, Katsumata M, Maruyama T, et al. Mid-term results of surgery for chronic thromboembolic pulmonary hypertension. Interact Cardiovasc Thorac Surg. 2009;9:626-9.

30. Gu S, Liu Y, Su PX, Zhai ZG, Yang YH, Wang C. Pulmonary endarterectomy for chronic thromboembolic pulmonary hypertension: preliminary exploration in China. Chin Med J. 2010;123:979-83.

31. van der Plas MN, Reesink HJ, Roos CM, van Steenwijk RP, Kloek JJ, Bresser P. Pulmonary endarterectomy improves dyspnea by the relief of dead space ventilation. Ann Thorac Surg. 2010;89:347-52.

32. de Perrot M, McRae K, Shargall Y, Pletsch L, Tan K, Slinger P, et al. Pulmonary endarterectomy for chronic thromboembolic pulmonary hypertension: the Toronto experience. Can J Cardiol. 2011;27:692-7.

33. van der Plas MN, Surie S, Reesink HJ, van Steenwijk RP, Kloek JJ, Bresser P. Longitudinal follow-up of six-minute walk distance after pulmonary endarterectomy. Ann Thorac Surg. 2011;91:1094-9.

34. Li YD, Zhai ZG, Wu YF, Yang YH, Gu S, Liu Y, et al. Improvement of right ventricular dysfunction after pulmonary endarterectomy in patients with chronic thromboembolic pulmonary hypertension: utility of echocardiography to demonstrate restoration of the right ventricle during 2-year follow-up. Thromb Res. 2013;131:e196-201

35. D’Armini AM, Morsolini M, Mattiucci G, Grazioli V, Pin M, Valentini A, et al. Pulmonary endarterectomy for distal chronic thromboembolic pulmonary hypertension. J Thorac Cardiovasc Surg. 2014;148:1005-12.

36. Jujo T, Sakao S, Ishibashi-Ueda H, Ishida K, Naito A, Sugiura T, et al. Evaluation of the microcirculation in chronic thromboembolic pulmonary hypertension patients: the impact of pulmonary arterial remodeling on postoperative and follow-up pulmonary arterial pressure and vascular resistance. PLoS One. 2015;10:e0133167.

37. de Perrot M, Thenganatt J, McRae K, Moric J, Mercier O, Pierre A, et al. Pulmonary endarterectomy in severe chronic thromboembolic pulmonary hypertension. J Heart Lung Transplant. 2015:34:369-75.

38. Shimura N, Kataoka M, Inami T, Yanagisawa R, Ishiguro H, Kawakami T, et al. Additional percutaneous transluminal pulmonary angioplasty for residual or recurrent pulmonary hypertension after pulmonary endarterectomy. Int J Cardiol. 2015; 183:138-42.

39. Cannon JE, Su L, Kiely DG, Page K, Toshner M, Swietlik E, et al. Dynamic risk stratification of patient long-term outcome after pulmonary endarterectomy: results from the UK National Cohort. Circulation. 2016;133: 1761-71.
40. Nierlich P, Ristl R. Perioperative extracorporeal membrane oxygenation bridging in patients undergoing pulmonary endarterectomy. Interact Cardiovasc Thorac Surg. 2015;22:181-7.

41. Richter MJ, Milger K, Tello K, Stille P, Seeger W, Mayer E, et al. Heart rate response during 6-minute walking testing predicts outcome in operable chronic thromboembolic pulmonary hypertension. BMC Pulm Med. 2016;16:96.

42. Leung Wai Sang S, Morin JF, Hirsch A. Operative and functional outcome after pulmonary endarterectomy for advanced thromboembolic pulmonary hypertension. J Card Surg. 2016;31:3-8.

43. Surie S. Identification of High-Risk Patients and Outcome in Chronic Thromboembolic Pulmonary Hypertension. Amsterdam: University of Amsterdam; 2016.

44. Jamieson SW, Kapelanski DP, Sakakibara N, Manecke GR, Thistlethwaite PA, Kerr KM, et al. Pulmonary endarterectomy: experience and lessons learned in 1,500 cases. Ann Thorac Surg. 2003;76:1457-64.

45. Freed DH, Thomson BM, Berman M, Tsui SS, Dunning J, Sheares KK, et al. Survival after pulmonary thromboendarterectomy: effect of residual pulmonary hypertension. J Thorac Cardiovasc Surg. 2011;141:383-7.

46. Saouti N, Morshuis WJ, Heijmen RH, Snijder RJ. Long-term outcome after pulmonary endarterectomy for chronic thromboembolic pulmonary hypertension: a single institution experience. Eur J Cardiothorac Surg. 2009;35:947-52.

47. Hartz RS, Byrne JG, Levitsky S, Park J, Rich S. Predictors of mortality in pulmonary thromboendarterectomy. Ann Thorac Surg. 1996;62:1255-60.

48. Hughes RJ, Jais X, Bonderman D, Suntharalingam J, Humbert M, Lang I, et al The efficacy of bosentan in inoperable chronic thromboembolic pulmonary hypertension: a 1-year follow-up study. Eur Respir J. 2006;28:138-43.

49. Jaï X, D'Armini AM, Jansa P, Torbicki A, Delcroix M, Ghofrani HA, et al. Bosentan for treatment of inoperable chronic thromboembolic pulmonary hypertension: BENEFiT (Bosentan Effects in iNopErable Forms of chronIc Thromboembolic pulmonary hypertension), a randomized, placebo-controlled trial. J Am Coll Cardiol. 2008;52:2127-34.

50. Kim NH, D'armini AM, Grimminger F, Grünig E, Hoeper MM, Jansa P, et al Haemodynamic effects of riociguat in inoperable/recurrent chronic thromboem bolic pulmonary hypertension. Heart. 2017;103:599-606.

51. Ghofrani HA, D’Armini AM, Grimminger F, Hoeper MM, Jansa P, Kim NH, et al. Riociguat for the treatment of chronic thromboembolic pulmonary hypertension. N Engl J Med. 2013;369:319-29.

52. Jenkins D, Madani M, Fadel E, D'Armini AM, Mayer E. Pulmonary endarterectomy in the management of chronic thromboembolic pulmonary hypertension. Eur Respir Rev. 2017;26:160111.

53. Yandrapalli S, Tariq S, Kumar J, Aronow WS, Malekan R, Frishman WH, et al Chronic thromboembolic pulmonary hypertension: epidemiology, diagnosis, and management. Cardiol Rev. 2018;26:62-72.

54. Ghofrani HA, Simonneau G, D’Armini AM, Fedullo P, Howard LS, Jaï X, et al Macitentan for the treatment of inoperable chronic thromboembolic pulmonary hypertension (MERIT-1): results from the multicentre, phase 2, randomised double-blind, placebo-controlled study. Lancet Respir Med. 2017;5:785-94.

55. Torbicki A. Macitentan for treatment of CTEPH: why MERIT merits attention. Lancet Respir Med. 2017;5:762-3.

56. Lang I, Gomez-Sanchez M, Kneussl M, Naeije R, Escribano P, Skoro-Sajer N, et al. Efficacy of long-term subcutaneous treprostinil sodium therapy in pulmonary hypertension. Chest. 2006;129:1636-43.

57. Skoro-Sajer N, Bonderman D, Wiesbauer F, Harja E, Jakowitsch J, Klepetko W, et al. Treprostinil for severe inoperable chronic thromboembolic pulmonary hypertension. J Thromb Haemost. 2007;5:483-9.

58. Joyce DL. Is the venoarterial extracorporeal membrane oxygenation circuit your frenemy? J Thorac Cardiovasc Surg. 2018;155:641-2.

59. Cevasco M, Takayama H. Extracorporeal membrane oxygenation: A bleeding patient's best friend? J Thorac Cardiovasc Surg. 2018;155:651-2.

60. Guth S, Wiedenroth CB, Wollenschläger M, Richter MJ, Ghofrani HA, Arlt M, et al. Short-term venoarterial extracorporeal membrane oxygenation for massive endobronchial hemorrhage after pulmonary endarterectomy. J Thorac Cardiovasc Surg. 2018;155:643-9.

Key Words: chronic thromboembolic pulmonary hypertension, mean pulmonary artery pressure, pulmonary endarterectomy, pulmonary thromboendarterectomy, pulmonary vascular resistance 